[18] Borodin, Yu. I., Trufakin, V. A., Michurina, S. V., Shurlygina, A. V. (2012). Structural and temporal organization of liver, lymphatic, immune and endocrine systems in violation of the light regime and the administration of melatonin. Novosibirsk: Manuskript, 207.

[19] Cutolo, M. (2012). Chronobiology and the treatment of rheumatoid arthritis. Current Opinion in Rheumatology, 24 (3), 312-318. doi: 10.1097/bor.0b013e3283521c78

[20] Li, W.-Q., Qureshi, A. A., Schernhammer, E. S., Han, J. (2013). Rotating Night-Shift Work and Risk of Psoriasis in US Women. Journal of Investigative Dermatology, 133 (2), 565-567. doi: 10.1038/ jid.2012.285

\title{
QUALITY OF LIFE OF PATIENTS WITH OVARIAN CANCER OF THE THIRD STAGE USING DIFFERENTIATED TREATMENT
}

\author{
Andriy Rybin \\ Department of Oncology \\ Odessa National Medical University \\ 2 Valihovsky lane, Odessa, Ukraine, 65082 \\ Andriy.Rybin@gmail.com
}

\begin{abstract}
The aim of this research was to assess the quality of life in patients with stage III ovarian cancer during the treatment period, depending on the applied therapeutic approaches.

A comparative analysis of the results of treatment of 350 patients with adenocarcinoma of the ovaries of III-IV stage, which have undergone suboptimal or non-optimal cytomelective surgery, was conducted. To assess the quality of life and to examine the relationship between changes in physical health and quality of life, patients in both groups were asked to complete the questionnaires EORTC QLQ-C30 and SF-36. According to the questionnaire of the EORTC QLQ-C30, the indicators of physical activity, the ability to do everyday affairs, were higher in the second group of patients who received differentiated treatment. The indicator of "social functioning" was also higher in the II group of patients. When evaluating the patients' liver on the scale of the questionnaire SF-36, it was found that the positive effect of differentiated therapy is maintained for 3 years. Life quality is an important criterion for evaluating the results of antitumor therapy, and when it is continuously monitored in patients with ovarian cancer the safety of treatment for patients could be improved, including at an advanced stage.
\end{abstract}

Keywords: ovarian cancer, treatment, prognostication, quality of life.

\section{Introduction}

Over the past twenty years, the world's scientific community has made a significant progress in the study of quality of life in patients with cancer. The increasing interest in this problem is due to revolutionary changes in the field of medical diagnostic technologies. The introduction of effective cytotoxication methods, the emergence of new chemotherapeutic agents, the widespread use of pharmacogenetic and pharmacogenomic approaches require a clinician to understand the basic laws of sanogenesis and the overall adaptation of the body at various stages of treatment of malignant neoplasms. The National Cancer Institute (NCI) recommends evaluating the effectiveness of treatment of oncopathology according to survival criteria and quality of life (QL) [1]. Evaluating quality of life not only helps in choosing a clinical decision but also avoids unwanted side effects. Data on QL in the dynamics after any medical intervention can improve the interaction of the patient and the physician, identify clinical priorities, including during the rehabilitation and palliative care.

The peculiarities of ovarian cancer (OC) evaluation in patients with ovarian cancer are due to several factors [2]. First of all, OC is an aggressive disease with a low survival rate and a high rate of relapse [3]. This disease is ranked first in terms of mortality among genital cancer in women with OC $46 \%$ for all stages and $31 \%$ for advanced stages [4]. Treatment of OC is based on radical surgical intervention and repeated courses of active chemotherapy. Stress, in which a woman lives 
from the moment of diagnosis, is associated with uncertainty and anxiety, fear of death and a number of characteristic symptoms associated with the disease itself (weight loss, discomfort and abdominal pain, ascites, general exhaustion), or with side effects of therapy (changes in the skin, baldness, urinary and stools incontinence, swelling, loss of appetite and taste, insomnia, etc.) affect its ability to adapt to social life and self-reliance. Often, in patients with pancreatitis, manifestations of anxiety, depression, which also significantly affect QL, are defined, which is today considered as one of the most informative indicators characterizing the degree of human adaptability to living conditions and general state of health and allows determining the need for medical and psychosocial adaptation [5]. In recent years, the study of health related quality of life (HRQL) develops as a separate medical science with its own research methods, evaluation criteria, scope, etc. It is based on the definition by the World Health Organization (WHO) as an individual correlation of a position in the community's life in the context of culture and society's values system with the goals of an individual, plans, opportunities and degree of general disorder [6]. That is, the perception by a person of her position in life, including physical, mental and social wellbeing, regardless of the quality of the environment in which he lives, the degree of satisfaction with a particular level of life and other components of psychological comfort [7].

In a narrower sense, HRQL reflects, first and foremost, the impact of disease and applied medical technologies on general well-being of patients and satisfaction with treatment. At OC the main attention of researchers is paid first of all to the QL at the beginning of active treatment, as a criterion for the effectiveness of one or another method of treatment. At the stage of screening and early diagnosis, QL is studied less frequently, mainly in high-risk subpopulations (genetic burden, preventive salpingo-oophorectomy) [8].

\section{Aim of research}

To assess the quality of life of patients with stage III ovarian cancer during the treatment period, depending on the therapeutic approaches applied.

\section{Material and methods}

The study, realized on the base of oncology department of Odessa national medical university (Odessa) during 2012-2016, conducted a comparative analysis of the results of treatment of 350 patients with the ovarian adenocarcinoma of stage III-IV, who have undergone suboptimal or non-optimal cytoreductive surgery. Based on our approach and with the help of markers of resistance to platinum preparations, all patients were divided into 2 groups.

In determining the probability of platinum refractoriness/platinum resistance, there was used the formula:

$$
\mathrm{R}=0,5 \times \mathrm{T}-0,5 \times \mathrm{G}+0,1 \times \mathrm{KA}+0,3 \times \mathrm{NO}+0,1 \times \mathrm{UA},
$$

where $\mathrm{R}$ is the risk of platinum resistance, with $\mathrm{R}>1.0$ the resistance to platinum is probable, with $\mathrm{R}>1.0$ the refraction to platinum is probable

$\mathrm{T}$ - compliance with the criteria formulated by Tyulyandin S. A. [2] (T (0-5);

$\mathrm{G}$ - presence of mutant alleles of BRCA1 5832insC and BRCA2 6174delAG polymorphisms in hetero- and homozygous variants $(\mathrm{G}(0-3)$;

$\mathrm{KA}$ - activity of catecholamines (KA (0-1);

$\mathrm{NO}$ - Expression of nitric oxide (NO (0-5);

$\mathrm{UA}$ - degree of hyperuricemia (UA $(0-1)$;

At $\mathrm{R}<1.0$ platinum resistance is unlikely, with $\mathrm{R}=1-1.5$ the resistance to platinum is probable, and at $\mathrm{R}>1.5$ the refraction to platinum is probable.

The first group (control group) - patients with serous OC $(n=50)$ who received standard adjuvant first-line platinum chemotherapy without a developed concept of differential treatment (cisplatin $75 \mathrm{mg} / \mathrm{m}^{2}$ intravenous infusion of hydration and forced diuresis every 3 weeks);

Group II (main group) - 300 patients who, based on the criteria for detecting the sensitivity of ovarian cancer to chemotherapy with platinum preparations, were divided into 3 subgroups depending on the predicted effect of platinum: 
1 subgroup $(\mathrm{n}=77)$ - patients with supposed platinum refraction, which treatment was started with chemotherapy of the second line (paclitaxel $175 \mathrm{mg} / \mathrm{m}^{2}$ intravenously every 3 weeks with standard premedication with corticosteroids, antihistamines and H2-histamine receptor blockers: $12 \mathrm{mg}$ of dexamethasone inside or intramuscular injection for 12 and 6 hours ranitidine $150 \mathrm{mg}$ and $50 \mathrm{mg}$ dimedrol $/ \mathrm{m}$ for $30-60$ minutes before injection. Special infusion systems that do not contain PVC were used. In case of failure to purchase paclitaxel patients were administered by the scheme HemA (doxorubicin $50 \mathrm{mg} / \mathrm{m}^{2}$ intravenous infusion on day 1 , gemcitabine $1000 \mathrm{mg} / \mathrm{m}^{2}$ intravenous infusion of 1, 8 day 21-day cycle PCT).

2 subgroup $(n=98)$ - patients with predictable resistance to platinum OC for whom was realized the correction of disorders of sanogenesis and dysregulatory disease (nitric oxide donator, detoxicant, drugs that reduce uric acid levels in blood, hyperthermic chemophorfusion HYPEC) against the backdrop of a standard adjuvant chemotherapy by first-line platinum drugs.

3 subgroup $(n=125)$ - the women with probably sensitive to platinum drugs OC, who have taken treatment with platinum according to standards (cisplatin $50 \mathrm{mg} / \mathrm{m}^{2}$ intravenous infusion of hydration and forced diuresis every 3 weeks).

To assess the QL and to study the relationship between changes in physical health and quality of life, patients in both groups were asked to complete the questionnaire EORTC QLQ-C30 [1]. Patients in the first and second groups filled the questionnaire EORTC QLQ-C30 simultaneously over the same period of time, corresponding to two courses of monochemotherapy.

The questionnaire EORTC QLQ-C30 includes 30 issues and consists of 5 functional scales: physical functioning $(\mathrm{PF})$, role-functioning $(\mathrm{RF})$, emotional functioning $(\mathrm{EF})$, cognitive functioning (CF), social functioning (SF); 3 scales of symptoms: weakness (FA), nausea/vomiting (NV) and pain (PA); Overall Quality of Life Scale (QL); 6 single points: dyspnea (DY), sleep disturbance (SL), anorexia (AP), constipation (CO), diarrhea (DI), financial difficulties (FI). The high values of the functional scales reflect the high/healthy level of functioning, while the high values of the symptomatic scales indicate how many clinical symptoms of cancer are. For mathematical processing of the data, the Scoring manual EORTC manual was used.

All patients were additionally questioned using the Russian-language version of the SF-36 questionnaire at the beginning of treatment and after the completion of treatment. The term of catamnestic observation was 36 months.

The SF-36 questionnaire contains 36 points, of which 35 are used to process points in 8 scales: physical functioning, role-playing, bodily pain, general health, viability, social functioning, emotional state, and mental health.

Quantitative assessment of the following indicators:

1. Physical Functioning (FF) (Physical Functioning - PF) reflects the degree of limitation of exercise physical activity including Self-service

2. Role Physical Functioning (RF) (Role-Physical Functioning - RP) - the influence of physical state on everyday roles activities (work, performance of daily duties).

3. Bodily Pain (BP) and its impact on the ability to engage in everyday activities, including work at home and abroad.

4. General Health $(\mathrm{GH})$ - Assessing your current health status and prospects for treatment.

5. Vital (F) (Vitality - VT) - a subjective assessment by the respondent of her vitality (energy, vitality, and others.) Over the past four weeks, feeling full of strength and energy or vice versa - exhausted.

6. Social Activity (SA) (Social Functioning - SF) is characterized as a subjective assessment by respondents of the level of their relationships with friends, colleagues, relatives during the last four weeks.

7. Role Emotional Functioning (REF) (Role Emotional - RE) is a subjective assessment by the respondent of the degree of limitation of her daily activities, caused by emotional problems in the last four weeks.

8. Mental Health (MH) describes the mood, the presence of depression, anxiety and a general indicator of positive emotions. Low rates indicate the presence of depressive, anxiety worries, mental illness. 
Scales are grouped into two general indicators of "physical component of health", or "physical status" (FS) and "psychological component of health", or "psychological status" (PS).

The determination of the probability of differences between the groups compared was performed using the $\chi^{2}$ criterion, taking into account the Yates correction for pair comparisons and Bonferroni corrections for multiple comparisons with the control group. Statistical processing is performed using the software STATISTICA 10.0 (StatSoftInc., USA) [9].

\section{Results}

In assessing the quality of life of patients with RA on the background of different treatments there were identified the following changes, presented below in Table 1.

Table 1

Indicators of the questionnaire EORTC QLQ-C30

\begin{tabular}{|c|c|c|c|c|c|}
\hline \multirow{2}{*}{ No. } & \multirow{2}{*}{ Subscales EORTC QLQ-C30 } & \multirow{2}{*}{ I group $(\mathrm{n}=\mathbf{5 0})$} & \multicolumn{3}{|c|}{ II group $(n=300)$} \\
\hline & & & IIA $(n=77)$ & IIB $(n=98)$ & IIC $(n=125)$ \\
\hline 1 & General condition of health & $40,3 \pm 1,6$ & $41,5 \pm 1,9$ & $43,8 \pm 1,4$ & $45,5 \pm 1,3$ \\
\hline 2 & Physical functioning & $41,1 \pm 1,4$ & $51,7 \pm 2,4$ & $53,6 \pm 1,7$ & $52,7 \pm 1,4$ \\
\hline 3 & Role of functioning & $44,4 \pm 1,9$ & $53,3 \pm 3,2$ & $51,6 \pm 2,5$ & $51,1 \pm 1,9$ \\
\hline 4 & Emotional functioning & $66,0 \pm 2,1$ & $69,5 \pm 3,0$ & $70,7 \pm 2,4$ & $71,7 \pm 1,8$ \\
\hline 5 & Cognitive functioning & $7,4 \pm 0,9$ & $7,0 \pm 0,9$ & $7,3 \pm 0,8$ & $7,2 \pm 0,7$ \\
\hline 6 & Social functioning & $38,5 \pm 1,3$ & $47,7 \pm 1,4$ & $49,9 \pm 1,3$ & $51,2 \pm 1,1$ \\
\hline 7 & Fatigue & $54,4 \pm 2,6$ & $52,9 \pm 1,9$ & $53,8 \pm 1,4$ & $55,3 \pm 1,2$ \\
\hline 8 & Nausea/Vomiting & $36,3 \pm 0,3$ & $12,2 \pm 1,4$ & $8,8 \pm 0,7$ & $6,9 \pm 0,3$ \\
\hline 9 & Pain & $57,7 \pm 3,3$ & $73,6 \pm 2,8$ & $74,4 \pm 2,1$ & $75,5 \pm 1,8$ \\
\hline 10 & Dyspnea & $33,3 \pm 2,3$ & $32,8 \pm 1,9$ & $33,5 \pm 1,8$ & $33,0 \pm 1,2$ \\
\hline 11 & Insomnia & $33,3 \pm 1,2$ & $35,8 \pm 1,6$ & $38,5 \pm 1,4$ & $41,1 \pm 1,1$ \\
\hline 12 & Loss of appetite & $44,4 \pm 2,3$ & $24,4 \pm 1,2$ & $25,5 \pm 1,2$ & $26,2 \pm 1,1$ \\
\hline 13 & Constipation & $38,9 \pm 2,7$ & $33,3 \pm 2,2$ & $31,6 \pm 1,6$ & $29,8 \pm 1,3$ \\
\hline 14 & Diarrhea & $7,7 \pm 0,2$ & $2,5 \pm 0,2$ & $2,8 \pm 0,1$ & $3,3 \pm 0,1$ \\
\hline 15 & Financial difficulties & $72,2 \pm 4,1$ & $22,2 \pm 1,1$ & $24,4 \pm 0,8$ & $25,2 \pm 0,7$ \\
\hline
\end{tabular}

According to the questionnaire of the questionnaire EORTC QLQ-C30, the physical activity indicators, that is, the ability to do everyday affairs, were higher in the second group of patients who received differentiated treatment. The indicator of "social functioning" was also higher in the II group of patients. Subclass "Cognitive functioning", which is responsible for concentration of attention, interest in the environment, involvement in information technology, etc., in the evaluation gave results that were equally low in both group I and group II. Among symptomatic scales, a significant increase was found on the Pain scale in Group II (on average, 75.0 \pm 4.1 ), less pronounced - in 
group I (57.7 \pm 3.3$)$. According to the "Fatigue" scale, no significant differences were observed in both groups. Abnormalities in subscales "Nausea/Vomiting" and "Lower appetite" were twice as likely to be observed in group I. "Financial difficulties" in patients of group I were three times higher in comparison with group II. The importance of the final points of the questionnaire EORTC QLQ-C30 “General Health" and "Quality of Life" was higher in patients in group II.

When evaluating the patients' liver on the scale of the questionnaire SF-36 it was established that the positive effect of differentiated therapy is maintained for three years (Fig. 1).

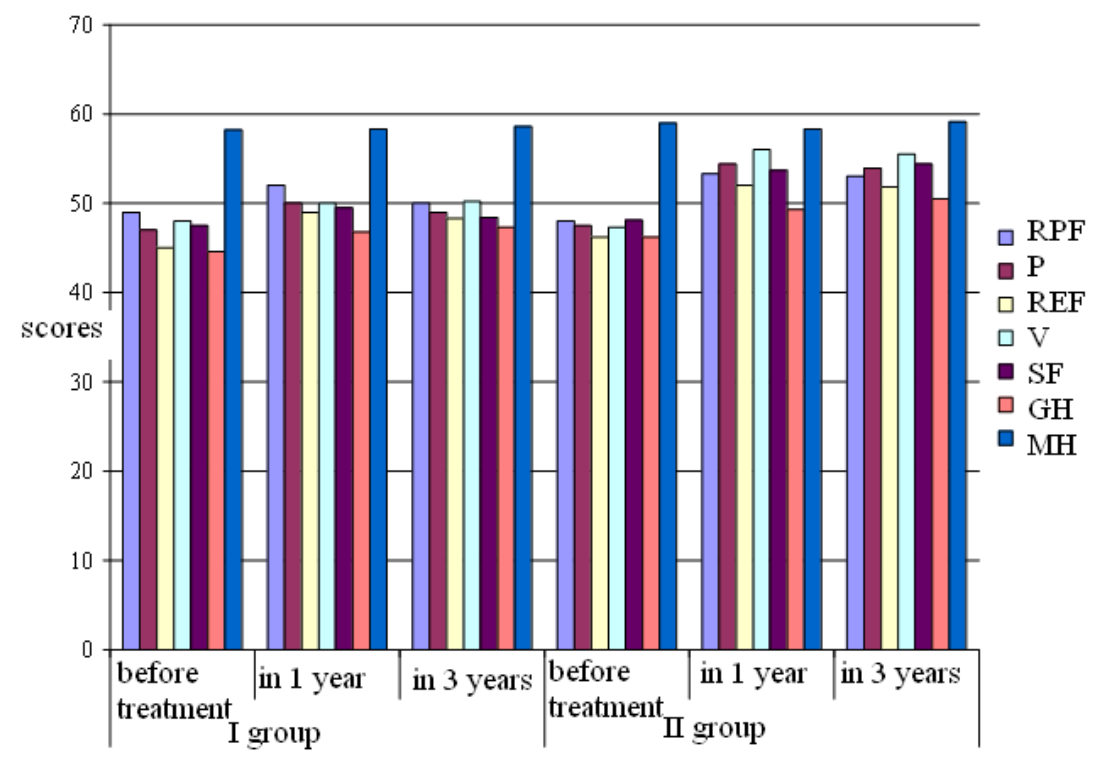

Fig. 1. Dynamics of indicators on the scale SF-36

The most pronounced positive changes were observed in patients of the second group under subclasses of role-based physical functioning, pain, vitality and social functioning.

\section{Discussion}

The choice of tactics for patients with platinum-resistant ovarian cancer depends on assessing the functional reserves of the body. In addition to the criteria formulated by Tyulyandin S. A. [2], it includes the markers of the platinum-resistance prognosis parameters such as genetic encumbrance (absence of BRCA1 5832insC and BRCA2 6174delAG mutant alleles in the hetero- and homozygous variants), increased levels of catecholamines, high NO expression in situ, degree of hyperuricemia. In women with the presence of these factors, it is expedient to use medicinal correction of disorderly disturbances (nitric oxide donators, detoxicants, anti-uremic drugs).

In the recently published systematic review [10] there was argued that despite the persistence of psychological and physical symptoms, treatment sequelae, sexual problems, and fear of recurrence in some survivors, most studies demonstrated that OC survivors generally have good QOL compared to healthy women. Sereika S .M. et al. (2015) consider that better understanding of the different propensity for symptoms based on age as well as their life quality can help clinicians not only address them but also choose chemotherapies to minimize them [11]. Ledermann J. A. et al. found the positive effect of chemiotherapy on life quality of patients suffering from ovarian cancer [12]. Phippen N. T. et al. (2017) evaluated the association between baseline quality of life and changes in QOL with progression-free disease and overall survival in advanced epithelial ovarian cancer [13]. OC relapse has a negative psychological and physical impact, highlighting the importance of time without recurrence and the need for effective treatment in the long term [14]. Quality of life predicts overall survival in women with platinum-resistant ovarian cancer as it was demonstrated in AURELIA substudy [15]. 
Overall, women with advanced-stage ovarian cancer who have survived for at least 8.5 years report good QOL and psychological adjustment. QOL of survivors with multiple recurrences is somewhat impaired compared to those with low recurrence. Limitations include a possible bias towards participation by healthier survivors, thus under-representing the level of compromise in long-term survivors. Health care practitioners should be alert to psychosocial issues faced by these long-term survivors to provide interventions that enhance QOL [16]. Bhugwandass CS et al. (2016) assessed differences in health-related quality of life between patients with early-stage ovarian cancer who did or did not receive chemotherapy as adjuvant treatment. They found that patients who receive adjuvant chemotherapy have a significantly worse score for 3 aspects of HRQOL [17].

Thus, HRQOL is an important criterion for evaluating the results of antitumor therapy [18] and when it is constantly monitored in patients with OC, it is possible to increase the safety of treatment for patients, including at an advanced stage [19]. However the current state of HRQOL use in the clinical practice in Ukraine requires improvement [20].

\section{Conclusions}

1. Differentiated treatment allows to improve the life quality in patients with OC during three years.

2. The use of a qualitative assessment of QL can be recommended as an additional criterion for the effectiveness of treatment of the serous OC.

\section{References}

[1] Hvastunov, R. A., Stolorenko, V. V., Lyutaya, E. D., Devyatchenko, T. F., Egin, E. I. (2004). Diagnosticheskie algoritmyi kompleksnogo monitoringa pri spetsialnom lechenii rasprostranennogo raka yaichnikov. Sovremennaya onkologiya, 6 (1), 11-16.

[2] Tyulyandin, S. A. (1999). Vyibor himioterapii pervoy linii u bolnyih rasprostranennyim rakom yaichnikov. Voprosyi onkologii, 4, 350-354.

[3] Shinde, S., Wanger, T., Novotny, P., Grudem, M., Jatoi, A. (2015). Disease-free ovarian cancer patients report severe pain and fatigue over time: prospective quality of life assessment in a consecutive series. European Journal of Gynaecological Oncology, 36 (2), 155-160.

[4] Doll, K. M., Pinheiro, L. C., Reeve, B. B. (2017). Pre-diagnosis health-related quality of life, surgery, and survival in women with advanced epithelial ovarian cancer: A SEER-MHOS study. Gynecologic Oncology, 144 (2), 348-353. doi: 10.1016/j.ygyno.2016.12.005

[5] Di Maio, M., Perrone, F. (2016). Lessons from clinical trials on quality-of-life assessment in ovarian cancer trials. Annals of Oncology, 27 (6), 961-962. doi: 10.1093/annonc/mdw153

[6] Ustun, T. B., Chatterji, S., Kostanjsek, N., Rehm, J., Kennedy, C., Epping-Jordan, J. et. al. (2010). Developing the World Health Organization Disability Assessment Schedule 2.0. Bulletin of the World Health Organization, 88 (11), 815-823. doi: 10.2471/blt.09.067231

[7] Zhurman, V. N., Eliseeva, E. V., Gulevich, A. P., Volkov, M. V. (2016). Otsenka kachestva zhizni bolnyih rakom yaichnikov I-III stadii po obschemu oprosniku EQ-5D i spetsialnomu oprosniku EORTC QLQ-C30. Kachestvennaya klinicheskaya praktika, 2, 46-51.

[8] Zhou, Y., Irwin, M. L., Ferrucci, L. M., McCorkle, R., Ercolano, E. A., Li, F. et. al. (2016). Health-related quality of life in ovarian cancer survivors: Results from the American Cancer Society's Study of Cancer Survivors - I. Gynecologic Oncology, 141 (3), 543-549. doi: 10.1016/j.ygyno.2016.04.006

[9] Halafyan, A. A. (2008). Statistica 6. Statisticheskiy analiz dannyih. Moscow: OOO «Binom-Press», 512.

[10] Ahmed-Lecheheb, D., Joly, F. (2016). Ovarian cancer survivors' quality of life: a systematic review. Journal of Cancer Survivorship, 10 (5), 789-801. doi: 10.1007/s11764-016-0525-8

[11] Thaker, P. H., Sereika, S. M., Arida, J., Edwards, R. P., Donovan, H. (2015). A comparison of monthly symptom reports for older ( $\geq 70$ years) versus younger $(<70$ years) women with recurrent ovarian cancer over 1 year. Journal of Clinical Oncology, 33(29), 85. doi: 10.1200/jco.2015.33.29_suppl.85

[12] Ledermann, J. A., Harter, P., Gourley, C., Friedlander, M., Vergote, I. B., Rustin, G. J. S. et. al. (2014). 885pdhealth-related quality of life (hrqol) during olaparib maintenance therapy in patients with plat- 
inum-sensitive relapsed serous ovarian cancer (psr soc) and a brca mutation (brcam). Annals of Oncology, 25 (4), 308-309. doi: 10.1093/annonc/mdu338.11

[13] Phippen, N. T., Secord, A. A., Wolf, S., Samsa, G., Davidson, B., Abernethy, A. P. et. al. (2017). Quality of life is significantly associated with survival in women with advanced epithelial ovarian cancer: An ancillary data analysis of the NRG Oncology/Gynecologic Oncology Group (GOG-0218) study. Gynecologic Oncology. doi: 10.1016/j.ygyno.2017.07.121

[14] Colombo, N., Lorusso, D., Scollo, P. (2017). Impact of Recurrence of Ovarian Cancer on Quality of Life and Outlook for the Future. International Journal of Gynecological Cancer, 27 (6), 1134-1140. doi: 10.1097/igc.0000000000001023

[15] Roncolato, F. T., Gibbs, E., Lee, C. K., Asher, R., Davies, L. C., Gebski, V. J. et. al. (2017). Quality of life predicts overall survival in women with platinum-resistant ovarian cancer: an AURELIA substudy. Annals of Oncology, 28 (8), 1849-1855. doi: 10.1093/annonc/mdx229

[16] Lutgendorf, S. K., Shinn, E., Carter, J., Leighton, S., Baggerly, K., Guindani, M. et. al. (2017). Quality of life among long-term survivors of advanced stage ovarian cancer: A cross-sectional approach. Gynecologic Oncology, 146 (1), 101-108. doi: 10.1016/j.ygyno.2017.05.008

[17] Bhugwandass, C. S., Pijnenborg, J. M. A., Pijlman, B., Ezendam, N. P. M. (2016). Effect of chemotherapy on health-related quality of life among early-stage ovarian cancer survivors: a study from the population-based PROFILES registry. Current Oncology, 23 (6), 556-562. doi: 10.3747/co.23.3243

[18] King, M. T., Stockler, M. R., Butow, P., O’Connell, R., Voysey, M., Oza, A. M. et. al. (2014). Development of the Measure of Ovarian Symptoms and Treatment Concerns. International Journal of Gynecological Cancer, 24 (5), 865-873. doi: 10.1097/igc.0000000000000167

[19] Lawrie, T. A., Winter-Roach, B. A., Heus, P., Kitchener, H. C. (2015). Adjuvant (post-surgery) chemotherapy for early stage epithelial ovarian cancer. Cochrane Database of Systematic Reviews. doi: 10.1002/14651858.cd004706.pub5

[20] Dubinina, V. H., Rybin, A. I. (2016). Yakist zhyttia khvorykh na rak yaiechnykiv yak indykator funktsionalnoi otsinky efektyvnosti adiuvantnoi platynovoi khimioterapii. Visnyk morfolohii, 22 (2), 328-331. 